\title{
Synthesis, Characterization and Dielectric Properties of Novel Metal Oxide - Phthalocyanine Nanocomposites
}

\author{
A. H. Salama* and A. M. Abdel-Karim \\ Physical Chemistry Department, National Research Centre, 33 El Bohouth St. (El- \\ Tahrir St. former) - Dokki, Giza, Egypt- P.O.12622.
}

\begin{abstract}
$\mathbf{O}^{\prime}$ RGANIC and metal-organic polymers which have electrical properties have opened up a promising field in material science and engineering. Phthalocyanine $\left(\mathrm{H}_{2} \mathrm{Pc}\right)$ and metal oxide- phthalocyanine $(\mathrm{MO}-\mathrm{Pc})$ where $(\mathrm{MO}=\mathrm{ZnO}, \mathrm{NiO}, \mathrm{FeO}$ and $\mathrm{CoO})$ were prepared by urea fusion technique. The prepared composites were identified by means of Fourier transform infrared spectroscopy (IR) and X-ray diffraction (XRD). The XRD data indicate that the ZnO$\mathrm{Pc}$ and NiO-Pc are highly crystalline and particle sizes are ranged from 28.4 to $57.2 \mathrm{~nm}$ and from 51.4 to 82.9 respectively. The dielectric properties including dielectric constant $\varepsilon^{\prime}$ and dielectric loss $\varepsilon$ " of the prepared composites were calculated from the experimental capacitance values in the frequency range $100 \mathrm{~Hz}$ to $5 \mathrm{MHz}$ and in the temperature range of $25^{\circ} \mathrm{C}$ to $120^{\circ} \mathrm{C}$. Generally, $\varepsilon^{\prime}$ are found to be decreased with increasing frequency and increase with increasing temperature. It is obvious that, appearance of peak for each MO in the dielectric loss suggests the presence of relaxing dipoles in the MO-Pc nanocomposites. The relaxation time $\tau$, activation enthalpy $\Delta H$ and the entropy change $\Delta S$ of the prepared composites were calculated. The obtained data were correlated to the nature of doping metal oxide.
\end{abstract}

Keywords: Metal oxide-phthalocyanine, dielectric constant, dielectric loss and relaxation time.

\section{Introduction}

In recent years, interest has been focused on the design of the smart and intelligent multifunctional nanomaterial as phthalocyanine $(\mathrm{Pc})$ for technological applications. Phthalocyanines $\left(\mathrm{H}_{2} \mathrm{Pc}\right)$ are aromatic and chemically stable compounds containing four pyrrole units and it can be considered as a weak dibasic acid. $\mathrm{H}_{2} \mathrm{Pc}$ has $18 \pi$-electron conjugated systems, in which different metal and non-metal ions can be included. A number of derivatives can be made in the macrocycle either by doping different central metal ions or by substitution of functional groups at the peripheral sites of the phthalocyanine ring. The metal atoms replace the two hydrogen atoms attached to the two isoindole group to form the highly stable metal phthalocyanines (M-Pc) with six membered chelate rings, through two covalent and two coordination bonds. Several research groups have focused on studying the various properties of organic semiconductor such as Metal-free $\mathrm{H}_{2} \mathrm{Pc}$ and/or metal-substituted phthalocyanine compounds M-Pc. Their essential properties are attributed to their efficient electron transfer abilities. It has dark colors so it is suitable for using $\mathrm{Pc}$ and its derivatives as dyes and pigments in textile industries[1].

On the other hand, the broad range of condensed phases, such as mono-crystals mesophases, Langmuir- Blodgett films etc.[2], has contributed to the progress of electronic and electrophotic devices depend on these compounds[3]. So, phthalocyanine have a large industrial application related to intrinsic semiconductors as optoelectronic devices, solar cells, information storage systems, electronic imaging and liquid crystal display [4-10]. Pc derivatives as NiPc, $\mathrm{CoPc}$ and $\mathrm{CuPc}$ were used as gas sensing devices also; $\mathrm{CuPc}$ has been used in organic light emitting diodes $[11,12]$.

The photosensitive properties of phthalocyanine compounds were closely related to the particle size and the specific surface area. The potential and sensitivity of photoreceptors rose rapidly with the particle size of phthalocyanine reducing from micrometer scale to nanometer scale. Therefore, it is great significance to explore simple and effective 
methods for fabrications of nano-sized phthalocyanine. Preparation methods of nanosized phthalocyanine mainly involve liquid phase direct reprecipitation, laser irradiation, mechanical grinding, gas condensation and sol-gel routes $[13,14]$. Phthalocyanine particles synthesized by a sol gel method have a narrow particle size distribution and photoconductive performance. Nevertheless, it was reported that the synthesis of nano-sized titanium-oxophthalocyanine (TiO-Pc) was carried out separately with this method, and the processes were too complicated to be scaled up to commercial production [15].

In dielectric material the charges become polarized in applied alternating electric field such that the negative and positive charges move in opposite directions. Dipole orientation and ionic conduction interact strongly at microwave frequencies; generally at low frequency the nanocomposites have higher dielectric permittivity than microcomposites. The metal oxide (MO) nanoparticles are attractive because of their excellent physical and chemical properties. MO has high charge capacity, safety and low cost. So polymer composite consisting of the metal oxide nanocomposites shows good dielectric response as well as good stability [16].

The doping of inorganic nanofillers into polymer has resulted in polymer nanostructure materials have multi-functional, high performance composites. Little attention has been paid to study the nanometric structure of polyvinylidenefluoride (PVDF)-zinc oxide (ZnO) nanocomposites [17]. The metal oxide addition leads to the increase in dielectric permittivity of the PVDF which allow faster movement of the polymer chains and faster alignment of the dipoles.

In this work, metal free $\left(\mathrm{H}_{2} \mathrm{Pc}\right.$ phthalocyanine, and metal oxide - phthalocyanine) (MO-Pc) composites, where $(\mathrm{MO}=\mathrm{ZnO}, \mathrm{FeO}, \mathrm{CoO}$ and $\mathrm{NiO})$ were synthesized from the reaction of phthalic anhydride with metal nitrate by urea fusion technique. The characterizations of the prepared samples were carried out using XRD and IR-spectra. Finally the dielectric properties of the prepared composites were carried out through the measurement of dielectric constant $\varepsilon$ ' and dielectric loss $\varepsilon$ ', within the frequency range $100 \mathrm{~Hz}$ to $5 \mathrm{MHz}$ and the temperature range from $20^{\circ} \mathrm{C}$ to $120^{\circ} \mathrm{C}$. The thermodynamic parameters such as the activation enthalpies $\Delta \mathrm{H}$ and the entropy changes $\Delta \mathrm{S}$ of dielectric relaxation were calculated for the prepared Egypt.J.Chem. 61, No.2 (2018) composites from the usual rate equation.

\section{Experimental}

Synthesis of $\mathrm{H}_{2} \mathrm{PC}$

The synthesis of Pc using phthalic anhydride as the precursor is a simple pathway by which Pc can be obtained with a high purity and recovery. $8.88 \mathrm{gm}$ (0.06 mole) of phthalic anhydride was added to a $500 \mathrm{ml}$ flask, followed by adding 30 gm of urea, $0.2 \mathrm{gm}$ of ammonium molybdate as a reaction promoter. The temperature was gradually raised to $190-200^{\circ} \mathrm{C}$, and maintained for 4 hours with continuous stirring. The reaction product was cooled and boiled with distilled water many times. The precipitate was washed in sequence with $2 \% \mathrm{HCl}$, dilute alkali, $25 \%$ methanol and acetone. Final purification was done by drying the sample at $200^{\circ} \mathrm{C}$ for 3 hours in a dry oven by which any traces of impurities were sublimed. A blue colored $\mathrm{H}_{2} \mathrm{Pc}$ was obtained.

\section{Synthesis of Metal oxide-Pc}

Cobalt, Nickel, Iron and Zinc oxide Phthalocyanine composites were prepared by the urea fusion technique in the dry method as follows: $8.88 \mathrm{gm}$ (0.06 mole) of phthalic anhydride was added to a $500 \mathrm{ml}$ flask, followed by adding 30 gm of urea, $0.2 \mathrm{gm}$ of ammonium molybdate as a reaction promoter and 0.01 mole of metal nitrate $\mathrm{MNiO}_{3}$ where, $\mathrm{M}=\mathrm{Co}, \mathrm{Ni}, \mathrm{Fe}$ and $\mathrm{Zn}$. The same process of preparation and purification of MO-Pc were followed as mentioned above. Dark colored pigments of $\mathrm{Pc}$ were obtained with different colored ranged from blue to green powders.

\section{Characterization}

FTIR confirms the presence of functional groups and XRD give information about the crystalinity and grain size of novel prepared composites.

\section{FTIR-spectra}

FTIR-spectra of pure $\mathrm{H}_{2} \mathrm{Pc}$ and the prepared metal oxide-Pc nanocomposites were recorded by using a Perkin Elmer model 1430 spectrophotometer at room temperature in the range $4000-400 \mathrm{Cm}^{-1}$ using $\mathrm{KBr}$ pellet technique.

\section{$X$-ray Diffraction analysis}

Structural analysis was performed for the prepared composites using X-ray diffractograms provided with computer- controlled X-ray diffractometer formally made by PHILIPSMPD X PERT equipped with $\mathrm{Cu}$ radiation $\mathrm{CuKa}$ $\left(\mathrm{K}=1.54056 \mathrm{~A}^{\circ}\right)$ the $\mathrm{X}$ pert diffractometer has 
the Bragg - Brenano geometry. The $\mathrm{X}$ - ray tube used was a copper tube operating at $40 \mathrm{kV}$ and 30 $\mathrm{mA}$. The scanning range was 20 to $80(2 \mathrm{~h})$ with a step size of $0.02(2 \mathrm{~h})$ and counting times of $35 /$ step. Quartz was used as the standard material to correct for the instrumental broadening.

X-ray powder diffraction (XRD) was performed at room temperature for predicting the crystal structure and calculating the particle size by using Scherer formula.

$$
\mathrm{L}=\mathrm{K} \lambda / \beta \cos \theta
$$

where $\mathrm{k}$ is the Scherer constant taken as $0.94, \lambda$ is the X-ray wavelength $\left(\mathrm{CuK}_{\alpha}=0.15406 \mathrm{~nm}\right)$, $\beta$ is the peak width of half-maximum, and $\theta$ is the Bragg diffraction angle ranged from $5^{\circ} \leq 2 \theta$ $\leq 80^{\circ}$.

\section{Transmission Electron Microscope Images}

The transmission electron microscope (TEM) images were taken for the prepared metal oxides using a JEDL model 1230.

\section{Dielectric Measurements}

The dielectric properties (dielectric constant $\varepsilon$ ' and dielectric loss $\varepsilon "$ ) were measured as disc of $12 \mathrm{~mm}$ diameter and thickness of $2 \mathrm{~mm}$ were prepared by pressing powdered samples at 10 tons $/ \mathrm{cm}^{2}$ and subjected to temperature range from $25^{\circ} \mathrm{C}$ to $120^{\circ} \mathrm{C}$ and frequency range from $100 \mathrm{~Hz}$ to $5 \mathrm{MHz}$ using HIOKI $3532 \mathrm{LCR}$ HiTester. The dielectric constant $\varepsilon$ ', of the prepared $\mathrm{H}_{2} \mathrm{Pc}$ and $\mathrm{MO}-\mathrm{Pc}$ composites were calculated from the measured capacitance according to the equation:

$$
, \varepsilon^{\prime}=C_{p} d / \varepsilon_{o} A
$$

Where $\mathrm{C}_{\mathrm{p}}$ is the measured capacitance, $\mathrm{d}$ is the thickness, $\varepsilon_{0}$ is the permittivity of free space equal to $8.854 \times 10^{-12} \mathrm{~F} / \mathrm{m}$ and $\mathrm{A}$ is the effective area of the sample.

$$
, \varepsilon^{\prime \prime}=\varepsilon^{\prime} \tan \delta
$$

The temperature dependence of $\tau$ was determined through the application of the theory of rate processes to molecular dipole relaxation. The frequencies corresponding to the maximum energy loss $\mathrm{F}_{\mathrm{m}}$ are used to calculate the relaxation times from the relation

$$
, \tau=1 / 2 \pi \mathrm{F}_{\mathrm{m}}
$$

The activation enthalpies and the entropy changes of dielectric relaxation has been calculated from the usual rate equation

$$
\operatorname{Ln}(\mathrm{T} \tau \mathrm{K} / \mathrm{h})=1 / \mathrm{T}\left(\Delta \mathrm{H}_{\varepsilon} / \mathrm{R}\right)-\left(\Delta \mathrm{S}_{\varepsilon} / \mathrm{R}\right) .
$$

Here $\Delta \mathrm{H}_{\varepsilon}$ and $\Delta \mathrm{S}_{\varepsilon}$ are the enthalpy of activation and the entropy change per mole for dipole relaxation. Thus, from the slope of the plot of Ln ( T $\tau \mathrm{K} / \mathrm{h}$ ) against $1 / \mathrm{T}, \Delta \mathrm{H}_{\varepsilon}$ can be obtained where $\Delta \mathrm{S}_{\varepsilon}$ obtained from the intercept of this representation.

\section{$\underline{\text { Results and Discussion }}$}

Characterization of Phthalocyanine Composites

We are succeeded in the preparation of metal free $\mathrm{Pc}\left(\mathrm{H}_{2} \mathrm{Pc}\right)$ and its stable nano-phthalocyanine metal oxide composites (CoO-Pc, FeO-Pc, NiO$\mathrm{Pc}$ and $\mathrm{ZnO}-\mathrm{Pc}$ ) by urea fusion technique. The composition and the structure of the prepared phthalocyanine composites as shown in Scheme 1 identified by IR- TEM images and XRD analysis.

\section{IR-Spectra}

FTIR spectra were recorded for both the $\mathrm{H}_{2} \mathrm{Pc}$ and its MO-Pc composites in the range of $400-4000 \mathrm{~cm}^{-1}$. The spectra are shown in Fig. 1. IR spectra of $\mathrm{H}_{2} \mathrm{Pc}$ exhibit a peak at $3431 \mathrm{~cm}^{-1}$ attributed to $\mathrm{N}-\mathrm{H}$ stretching vibration peak and the peaks around $1719 \mathrm{~cm}^{-1}$ can be correlated with $\mathrm{C}=\mathrm{N}$ stretching vibration[18]. The strong peak at $740 \mathrm{~cm}^{-1}$ and $1110 \mathrm{~cm}^{-1}$ are considered to be associated with the N-H out of plane and in plane deformation respectively. The broad band observed at around $3200 \mathrm{~cm}^{-1}$ was assigned to $\mathrm{CH}_{2}$ stretching vibration. Broad peak of $\mathrm{CH}$ group at $1590 \mathrm{~cm}^{-1}$ and strong peak pointed for presence of C- $\mathrm{C}$ stretching vibration of phenyl ring around $2360 \mathrm{~cm}^{-1}[19]$. The peaks of MOPc spectra assigned at around $680 \mathrm{~cm}^{-1}$ shift towards lower wavenumber, due to the strong interaction of metal oxide with nitrogen atom in Pc to form a coordination bond. The observed frequencies of metal free phthalocyanine and its nano metal oxides composites are listed in Table 1.

TEM images of prepared nano metal oxides $-P C$ composites

The nano- metal oxides-Pc composites are investigated by transmission electron microscope and its results are shown in Fig. 2. From TEM images, all the prepared composites are in the nano scale and show definite crystal shape with 75-82 nm size range. 


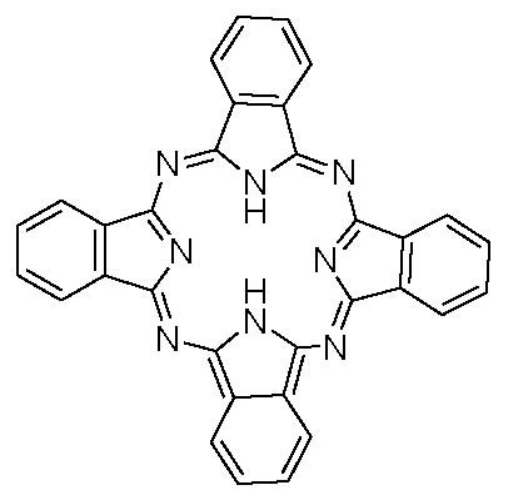

$\mathrm{H}_{2} \mathrm{P}_{\mathrm{C}}$

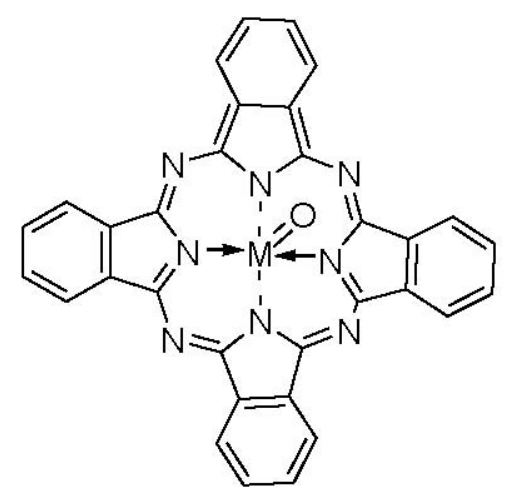

MO-P ${ }_{C}$

Scheme 1. $\mathrm{H}_{2} \mathrm{P}_{\mathrm{c}}$ and MO-P
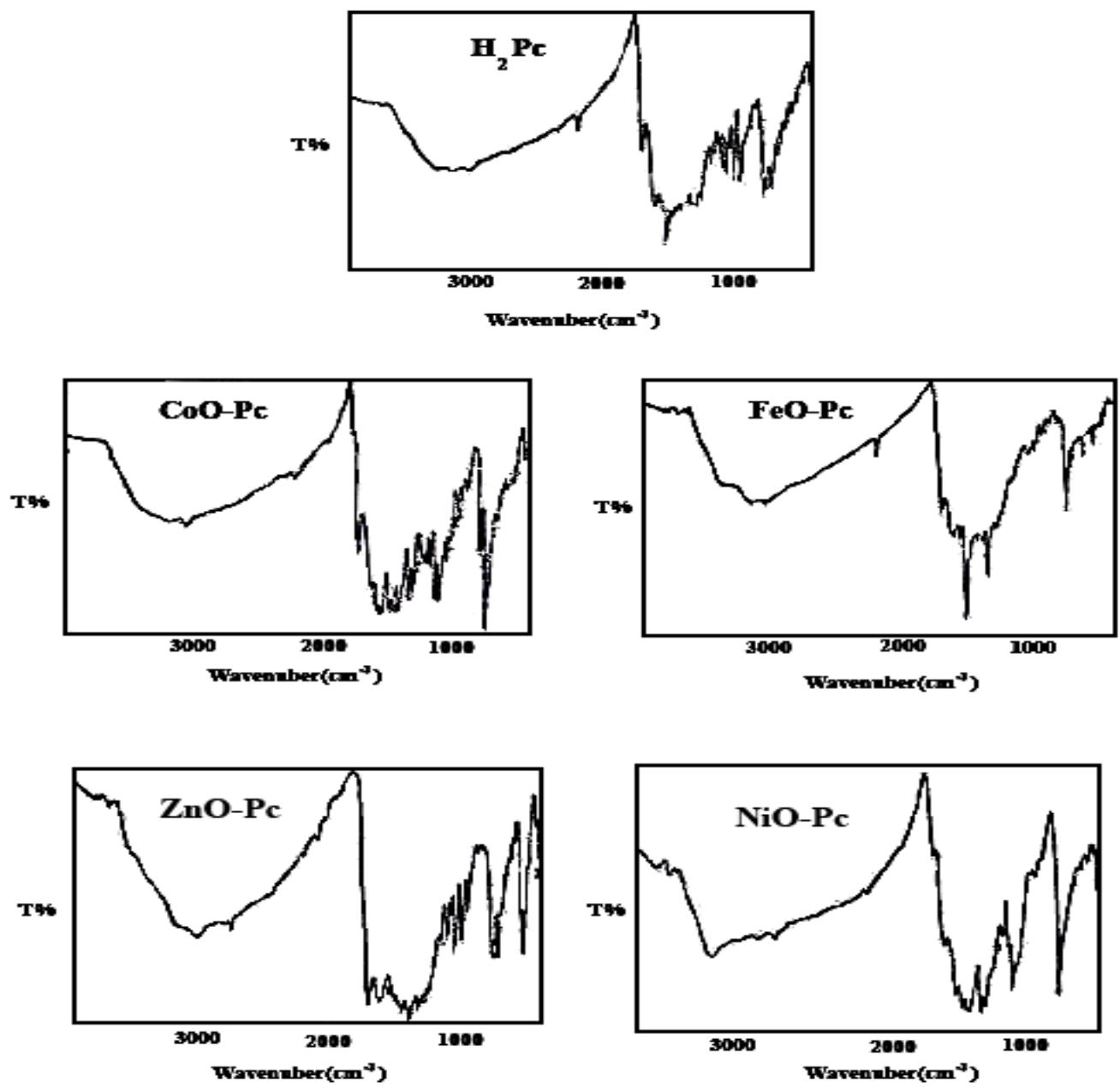

Fig.1. IR spectra of HPc and MO-Pc.

Egypt.J.Chem. 61, No.2 (2018) 
TABLE 1. Infra-Red Spectra of $\mathrm{H}_{2} \mathrm{Pc}$ and the prepared MO-Pc nanocomposites.

\begin{tabular}{|c|c|c|c|c|c|}
\hline & $\mathrm{H}_{2} \mathrm{Pc}$ & FeO-Pc & $\mathrm{CoO}-\mathrm{Pc}$ & NiO-Pc & $\mathrm{ZnO}-\mathrm{Pc}$ \\
\hline $\mathrm{C}-\mathrm{N}$ & $1298-1257$ & $1294-1362$ & $1160-1285$ & 1285 & 1399 \\
\hline $\begin{array}{l}\text { Conjugated } \\
\text { system }\end{array}$ & $\begin{array}{c}\text { 1009-1062-1113- } \\
1131\end{array}$ & $1059-1089-1190$ & $1010-1032-1120$ & $\begin{array}{c}1080-114- \\
1160\end{array}$ & 1088-1117 \\
\hline $\mathrm{CH}$ & $771-726-711$ & $717-764$ & $776-754-727$ & 719 & 722 \\
\hline - $\mathrm{CH}$ aromatic & $955-834$ & $854-904-960$ & $943-912-808$ & $944-909$ & 885 \\
\hline
\end{tabular}
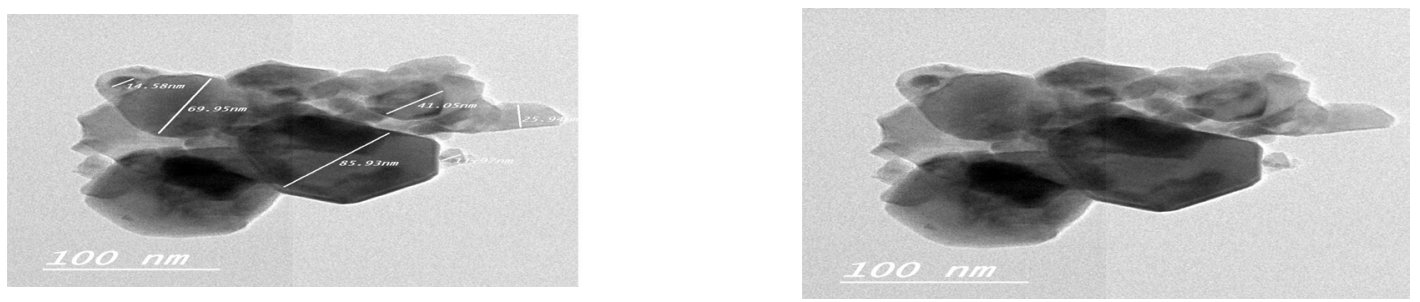

H2Pc
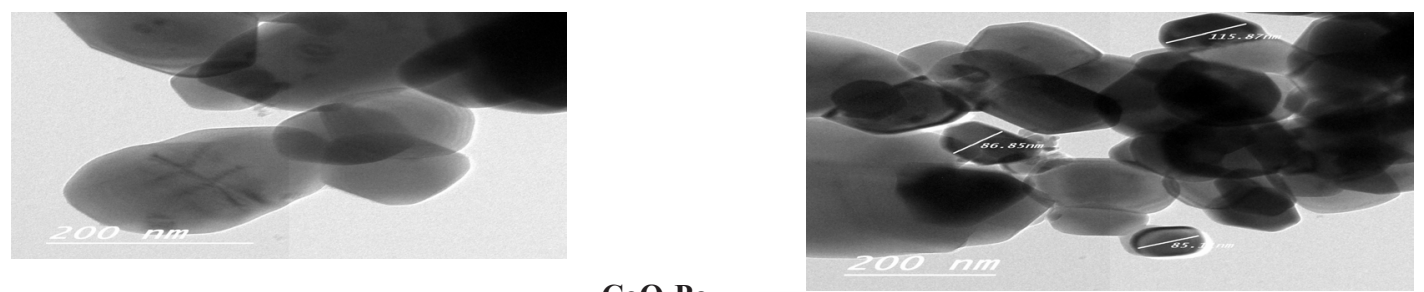

CoO-Pc
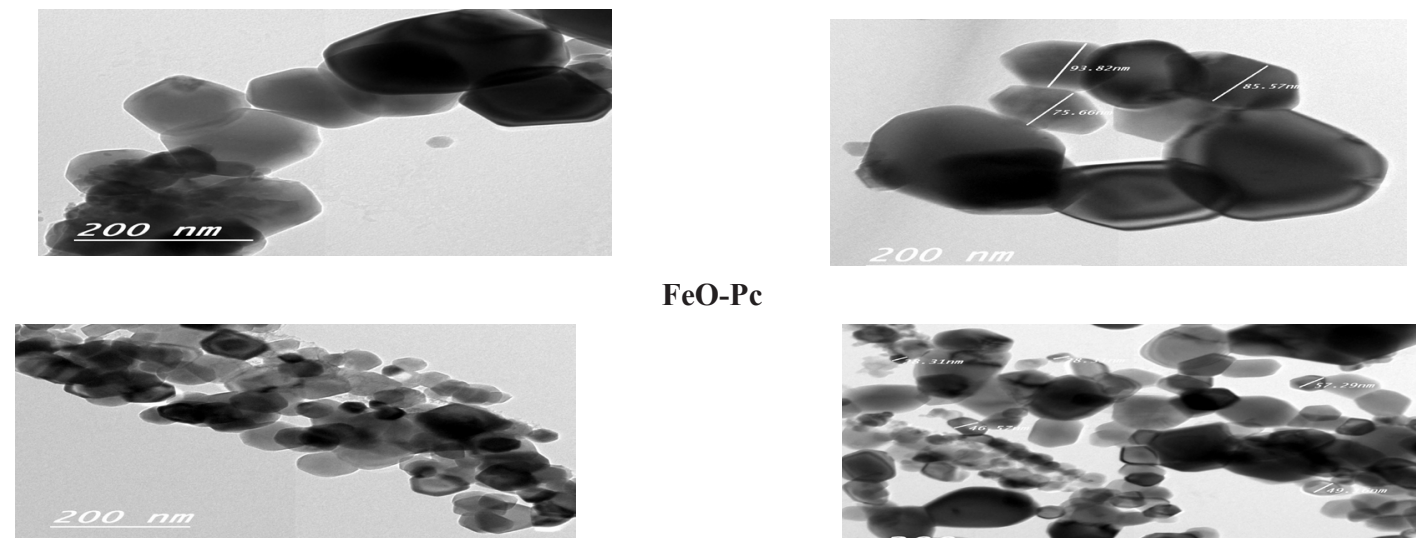

FeO-Pc
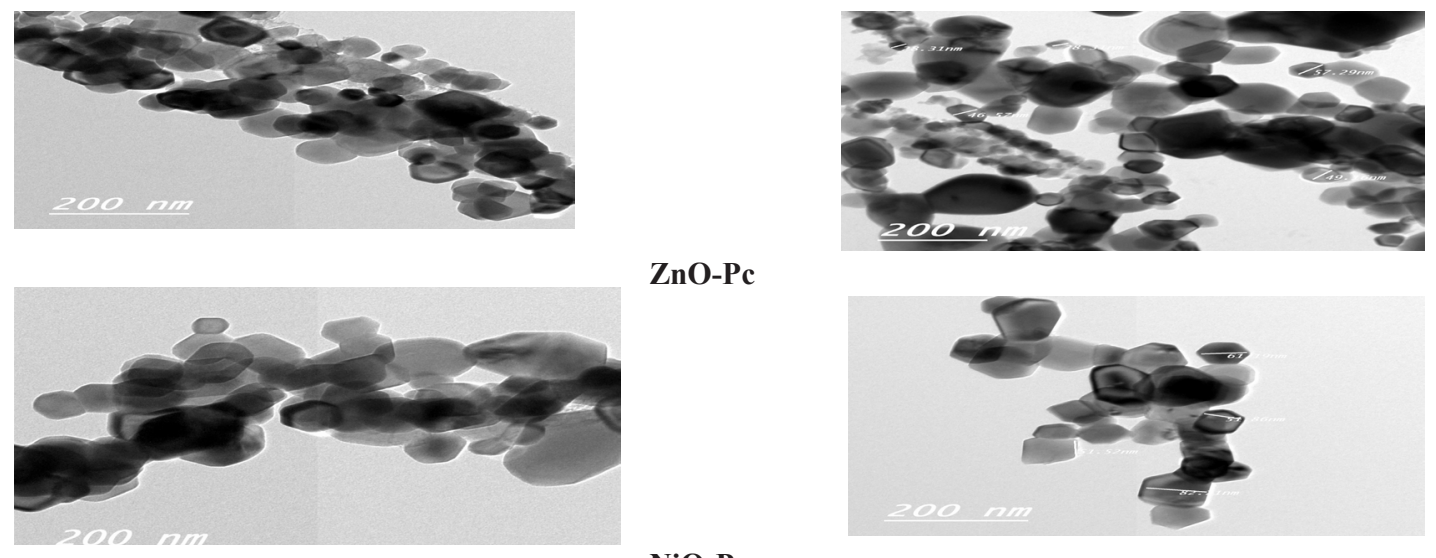

ZnO-Pc

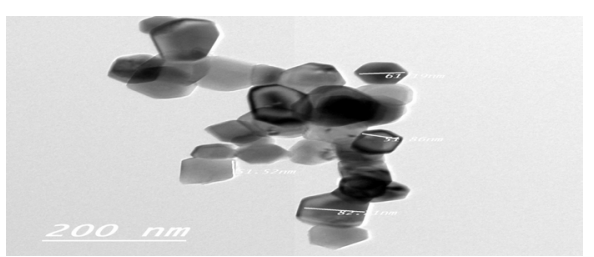

NiO-Pc

Fig. 2. TEM of H2Pc and its nano metal oxide composites 


\section{$X$-Ray Diffraction studies}

The X-ray powder diffraction pattern of $\mathrm{H}_{2} \mathrm{Pc}$ and its metaloxo-PC (ZnO-Pc, FeO-Pc, $\mathrm{NiO}-\mathrm{Pc}$ and $\mathrm{CoO}-\mathrm{Pc})$ has been studied at room temperature. The data of $\mathrm{d}\left(\mathrm{A}^{\circ}\right)$ values, $2 \theta$ and the crystal size of the prepared composites are given in Table 2 and are graphically represented in Fig.3. The XRD pattern of $\mathrm{H}_{2} \mathrm{Pc}$ showed one broad peak with high intensity from $10^{\circ}$ to $20^{\circ}$ and another broad one with low intensity from $20^{\circ}$ to $35^{\circ}$ which indicates the formation of MF $\mathrm{PC}$ with low crystalline nature.

On the other hand the XRD patterns for the MO-Pc are rich with high and medium intensity peaks in the range of $4^{\circ}-80^{\circ}$ besides the two broad bands observed for MF-Pc. The presence of this high and medium intensity peaks ensure the presence of the metal oxide as separate phase in the matrix of the conjugated phthalocyanine composites expect for $\mathrm{FeO}-\mathrm{Pc}$ and $\mathrm{CoO}-\mathrm{Pc}$ composites where the characteristic peaks are broad and less intense, indicating that the iron oxide and cobalt oxide suppers crystals to grow which can be attributed to its encapsulation by phthalocyanine and the ability of these metal oxides to form amorphous metal (some authors called them bulk metallic glass) [20] as a result of their high magnetic character of $\mathrm{Fe}^{2+}$ and $\mathrm{Co}^{2+}$, where $\mathrm{Fe}^{2+}$ has 4 unpaired electrons occupied $3 \mathrm{~d}$ orbital and has a magnetic moment equal to $5.1-5.7 \mu \mathrm{B}$ and $\mathrm{Co}^{2+}$ has 3 unpaired electrons occupied $3 \mathrm{~d}$ orbital and has a magnetic moment equal to $4.2-4.8 \mu \mathrm{B}[21$ - 23].

For Pure $\mathrm{ZnO}$ powder there are sharp peaks at $31.837^{\circ}, 34.502^{\circ}, 36.334^{\circ}, 47.650^{\circ}, 56.726^{\circ}$, $63.012^{\circ}$ and $68.114^{\circ}$ corresponding to diffraction planes and d value of 2.8112 (100), 2.5996 (002), 2.4702 (101), 1.9092 (102), 1.6239 (110), 1.4763 (103), 1.4060 (200), 1.3777 (112) and 1.3590 (201) are observed and they are in accordance with the $\mathrm{ZnO}$ structure (Reference pattern JCPDS 5-0664). As shown in Fig.2, these peaks are observed in XRD pattern of $\mathrm{ZnO}-\mathrm{Pc}$ composite and extra peak at $15.3^{\circ}$ of Pc which indicates the presence of $\mathrm{ZnO}$ in $\mathrm{Pc}$ and no peaks of impurity were observed suggesting that the high purity $\mathrm{ZnO}-\mathrm{Pc}$ was obtained $[18,22]$. We also found that XRD pattern of $\mathrm{NiO}-\mathrm{Pc}$ is the same pattern of NiO (Reference pattern JCPDS No. 04-0835) and extra peak characteristic for the presence of phthalocyanine. Referring to Table 2, we found the crystal size of $\mathrm{ZnO}-\mathrm{Pc}$ ranged from $28.4 \mathrm{~nm}$ to $57.2 \mathrm{~nm}$, for $\mathrm{NiO}-\mathrm{Pc}$ ranged from $51.1 \mathrm{~nm}$ to

Egypt.J.Chem. 61, No.2 (2018)
$82.1 \mathrm{~nm}$ while it ranges from $85-115.2 \mathrm{~nm}$ for $\mathrm{CoO}-\mathrm{Pc}[24,25]$. these values matches well with that obtained from TEM images.

\section{Dielectric properties}

In general, the conjugated organic polymer is insulating or sometimes semiconductors. Electrons cannot move along polymers chain because of the lack of charged carriers and also the different bond lengths along the polymer chain. To make these polymers conductive, mobile charge carriers (doping) must be introduced by a series of oxidations or reductions, that similar to the changes that occurs in the electrical properties of inorganic semiconductor [26].

Electrical study of composites by measuring dielectric properties at different temperatures and frequency is one of the most important characters to investigate their use in electrical devices. Basically, dielectric constant $\varepsilon$ ' is the measure of how easily a material is polarized in the presence of external electric field. for heterogeneous dielectric materials the changes in the value of $\varepsilon$ as a function of frequency are attributed to the space charges polarization (Maxwell- Wagner-Sillar) owing to moving of free charges at the interfaces of the composites and dielectric relaxation due to segmental movement [27,28]. When measuring the dielectric constant of composites at different frequencies, by applied electric field, the energies of the dipoles situated on each side of the potential barrier will be changed such that, the dipoles parallel to the field have lower potential energy than those anti-parallel to the field. The dipoles will perform oscillation at a resonance frequency about their equilibrium position and their transition from one position to another will be associated with the possibility of rotation.

Figure 4 shows the variation of $\varepsilon$ ' with frequency ranged from $100 \mathrm{~Hz}$ to $5 \mathrm{MHz}$ at different temperatures ranged from $20^{\circ} \mathrm{C}$ to $120^{\circ} \mathrm{C}$ for $\mathrm{H}_{2} \mathrm{Pc}$ and its metal oxide composites. For all sample under study it is obvious that, the $\varepsilon$ ' have a high value then decrease with increasing the frequency reached a low value independent on frequency at higher one. Similar behaviors have been obtained for $\mathrm{CuPc}, \mathrm{ZnPc}$ and $\mathrm{CoPc}$ as previously reported for $\mathrm{Pc}$ metal composites [29, 30].

At lower frequencies dielectric constant $\varepsilon^{\prime}$ 

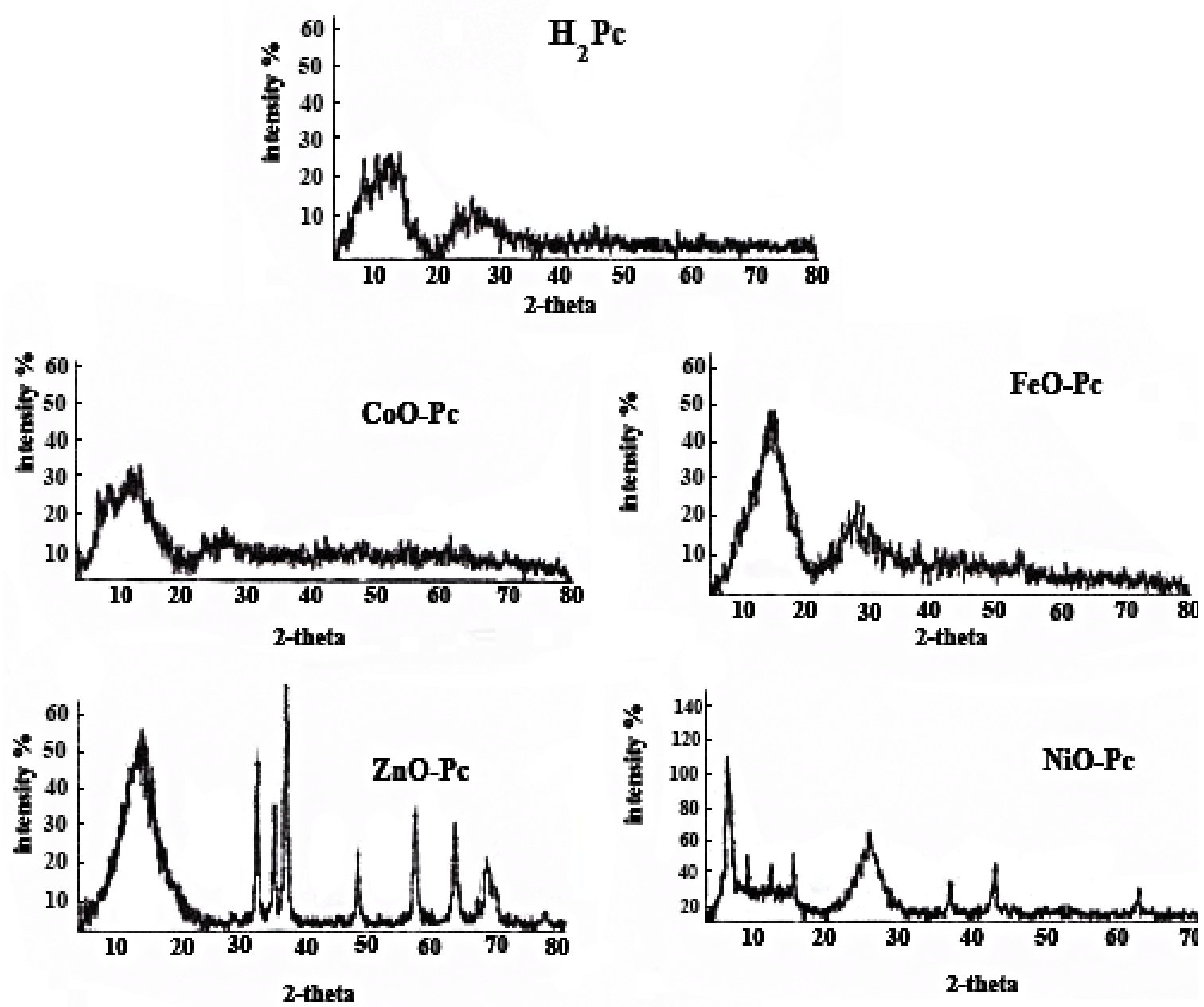

Fig. 3. XRD spectra of $\mathrm{H} 2 \mathrm{Pc}$ and MO-Pc composites.

TABLE 2. X-ray diffraction data (20, d-spacing and intensity of the prepared MO-Pc nanocomposites.

\begin{tabular}{|c|c|c|c|c|c|c|c|c|}
\hline \multicolumn{3}{|c|}{ CoO-Pc } & \multicolumn{3}{|c|}{$\mathrm{NiO}-\mathrm{Pc}$} & \multicolumn{3}{|c|}{$\mathrm{ZnO}-\mathrm{Pc}$} \\
\hline $2 \theta$ & $\begin{array}{c}\text { D-spacing } \\
\left(\mathbf{A}^{0}\right)\end{array}$ & $\begin{array}{c}\text { grain } \\
\operatorname{size}(n m)\end{array}$ & $2 \theta$ & $\begin{array}{c}\text { d-spacing } \\
\left(\mathbf{A}^{0}\right)\end{array}$ & $\begin{array}{c}\text { grain } \\
\operatorname{size}(n m)\end{array}$ & $2 \theta$ & $\begin{array}{c}\text { d-spacing } \\
\left(\mathrm{A}^{0}\right)\end{array}$ & $\begin{array}{c}\text { grain } \\
\text { size(nm) }\end{array}$ \\
\hline 6.99 & 12.62 & 86.8 & 6.86 & 12.88 & 51.5 & 31.72 & 2.82 & 28.4 \\
\hline 8.79 & 10.05 & 85.7 & 9.57 & 9.24 & 60.2 & 34.38 & 2.61 & 49.2 \\
\hline 25.93 & 3.08 & 88.8 & 12.75 & 6.94 & 62.5 & 36.19 & 2.48 & 28.3 \\
\hline \multirow[t]{7}{*}{29.94} & 2.98 & 115.2 & 15.79 & 5.61 & 60.3 & 47.47 & 1.91 & 52.2 \\
\hline & & & 26.13 & 3.41 & 51.1 & 56.54 & 51.5 & 50.4 \\
\hline & & & 37.17 & 2.42 & 55.5 & 62.81 & 55.5 & 40.2 \\
\hline & & & 43.25 & 2.09 & 61.3 & 66.30 & 61.3 & 55.3 \\
\hline & & & 62.88 & 1.48 & 82.1 & 67.77 & 82.1 & 37.1 \\
\hline & & & & & & 69.09 & 1.35 & 49.1 \\
\hline & & & & & & 76.87 & 1.24 & 57.2 \\
\hline
\end{tabular}



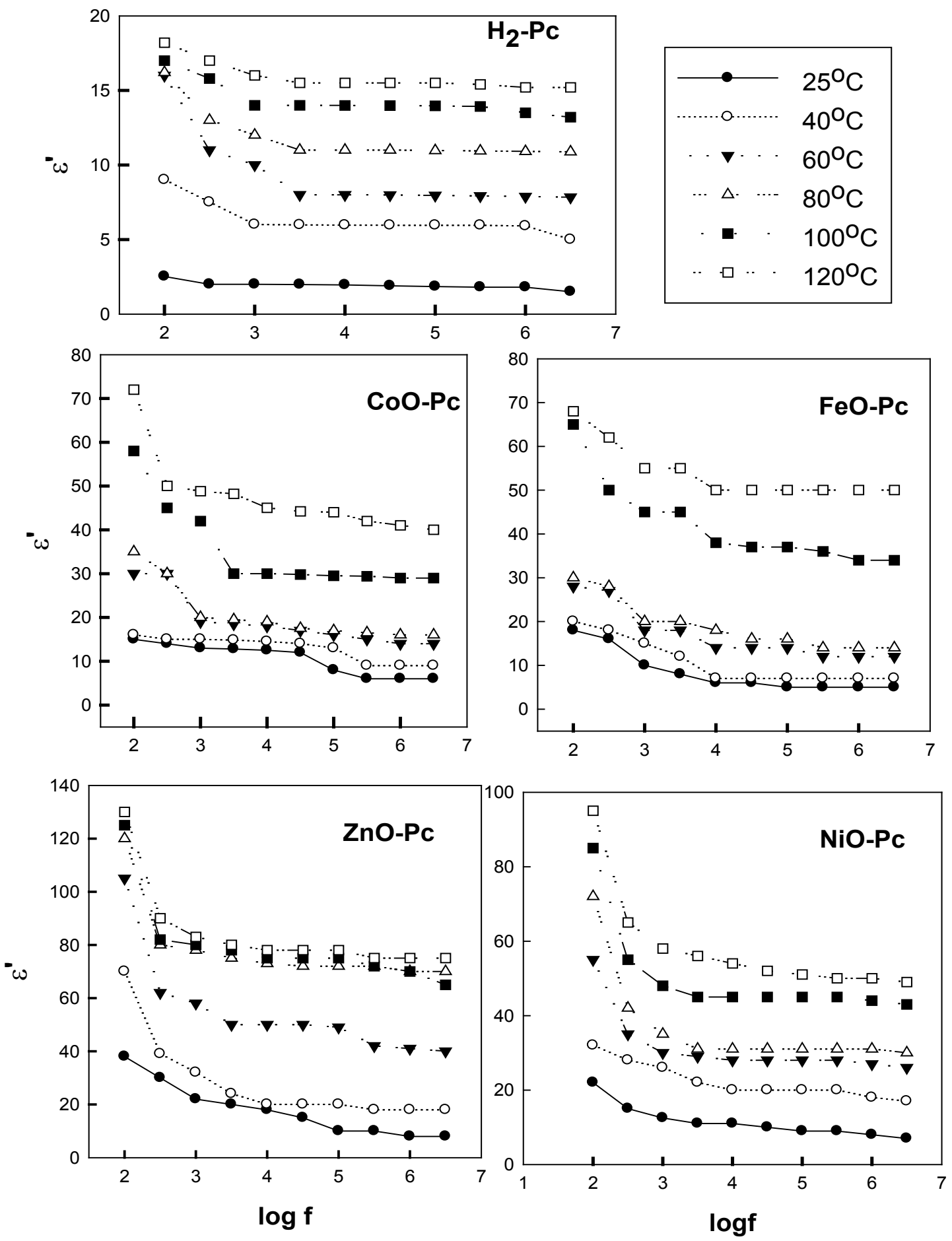

Fig.4. Variation of dielectric constant $\varepsilon^{\prime}$ with frequency at different temperatures for H2Pc and MO-Pc. 
of $\mathrm{H}_{2} \mathrm{Pc}$ has a high value due to the presence of four polarizations (space charge, orientation, electronic, and ionic polarization). As the frequency increases, the larger dipolar groups find it difficult to orient hence $\varepsilon$ ' decreases and its low value at higher frequencies may be due to the loss of significance of these polarizations gradually.

Similarly, MO-Pc have high value of $\varepsilon^{\prime}$ at low frequencies reveals that the system exhibits strong interfacial polarization (IP) between metal oxides and phthalocyanine. IP occurs when there is an accumulation of charge at interface within the material when electric field is applied. This interfacial polarization is particularly dominant at low frequencies and in conjugated polymers. MO displays strong Ionic polarization due to $\mathrm{M}^{2+}$ and $\mathrm{O}^{2-}$ ions thus has a high permittivity value $[31,32]$. The dielectric of MO-Pc nanocomposites decrease with increasing frequency due to the variation in the applied electric field is very rapid for the dipoles to align themselves. One can note from Fig. 4, that, at definite temperature as $120^{\circ} \mathrm{C}$ and with increasing frequency from $100 \mathrm{~Hz}$ to $5 \mathrm{MHz}$ the obtained data for dielectric constant decreased from 18 to 15 for $\mathrm{H}_{2} \mathrm{PC}$, from 130 to 75 for $\mathrm{ZnO}-\mathrm{PC}$, from 95 to 49 for NiO-Pc, from 72 to 40 for $\mathrm{CoO}-\mathrm{Pc}$ and for $\mathrm{FeO}-\mathrm{Pc}$ decrease from 68 to 50 .

To understand the effect of temperature on electrical response of composite we studied the variation of dielectric constant with temperature at definite frequencies as shown in Fig. 5 . At lower temperature, as the dipoles are rigidly fixed in the dielectric, the field cannot change the condition of dipoles. But on increasing the temperature the dipoles somewhat become free and they reply to the applied electric field [33] enhancing the ease of the orientation polarization of polar groups and polar bonds such as (O-M bonds and M-N bonds) [34]. So the effect of neighboring atoms or molecules decreases with increasing temperature, hence dielectric permittivity is also increased with the temperature.

Figure 6 represents the variation of $\varepsilon^{\prime}$ of $\mathrm{H}_{2} \mathrm{Pc}$ and $\mathrm{MO}-\mathrm{Pc}$ at temperature at $1 \mathrm{KHz}$, it is obvious that, the dielectric constant $\varepsilon^{\prime}$ obtained for $\mathrm{H}_{2} \mathrm{Pc}$ increases slowly at all temperature range. Dielectric constant $\varepsilon^{\prime}$ of MO-Pc composites increase slowly from $20^{\circ} \mathrm{C}$ to $80^{\circ} \mathrm{C}$ then fast increase from $80^{\circ} \mathrm{C}$ to $120^{\circ} \mathrm{C}$. The value of $\varepsilon^{\prime}$ for $\mathrm{H}_{2} \mathrm{Pc}$ was varied from 2.2 to 16.1 and that recorded for $\mathrm{FeO}-\mathrm{Pc}$, $\mathrm{CoO}-\mathrm{Pc}$, NiO-Pc, and $\mathrm{ZnO}-\mathrm{Pc}$ were varied from 8.1 to 55.3 , from 13.2 to 55.6 , from 14.3 to 60.4 , and from 22.1 to 83.3 respectively. The increase in $\varepsilon^{\prime}$ values with different metal oxide may be due to change in the free volume as we have different metals with different atomic radii as well as the magnitude of dipole-dipole interaction and segmental mobility. Moreover, the recorded high values of $\varepsilon^{\prime}$ for $\mathrm{ZnO}-\mathrm{PC}$ followed by NiO-Pc. The high values of dielectric constant $\varepsilon^{\prime}$ recorded for $\mathrm{ZnO}-\mathrm{Pc}$ is a result of high polarization [35], also $\mathrm{ZnO}-\mathrm{Pc}$ and $\mathrm{NiO}-\mathrm{Pc}$ have high crystalline structure and nano size range as explained earlier in XRD spectral analysis.

Figure 7 shows the variation of dielectric $\operatorname{loss} \varepsilon$ " with frequency at different temperatures, For all the prepared MO-Pc composites the dielectric absorption bands appear suggests the presence of relaxing dipoles in the prepared nanocomposites. Generally, the calculated $\varepsilon^{\prime \prime}$ spectrum contains contribution from two sources: dipolar orientation of polar groups and diffusion of free charge carrier and it's trapping in the holes. When interfacial polarization occurs it can be written as

$$
\varepsilon_{\text {mean }}^{\prime \prime}=\varepsilon^{\prime \prime}{ }_{D}+\varepsilon^{\prime \prime}{ }_{\mathrm{dc}}+\varepsilon^{\prime \prime}{ }_{i p}
$$

Where $\varepsilon^{\prime \prime}$ is orientation polarization (Debye type), $\varepsilon^{\prime \prime}{ }_{\text {dc }}$ is DC conduction and $\varepsilon^{\prime \prime}{ }_{\text {ip }}$ is interfacial polarization [36].

Dielectric loss decreases with increasing frequency above the critical frequency $F_{m}$ related to highest energy loss more than that required for activation and also with increasing temperature $\varepsilon$ " decreases so relaxation peak shifts towards higher frequency side suggesting the speed up of the relaxation time [37].

The various relaxation processes can be classified as $\alpha$ - and $\beta$ - relaxation. The $\alpha$ relaxation is mainly existing in an extremely crystallized polymer and is attributed to the movement of the main chain in the crystalline phase, while in $\beta$-relaxation is due to amorphous part in amorphous materials. When measuring the dielectric properties of organic samples at different frequencies, by an applied electric field, the energies of the dipoles situated on each side of the potential barrier will be changed such that, the dipoles parallel to the field have lower potential energy than those anti-parallel to the field. The dipoles will perform oscillation at a resonance frequency about their equilibrium position and their transition from one position

Egypt.J.Chem. 61, No.2 (2018) 
to another will be associated with the possibility of rotation. So the rotational polarization plays a significant role in dielectric relaxation. One can conclude that the relaxation time depends on temperature. The rotation of the dipoles associated with jumping over the potential barriers, hindering rotation can be taken as a model to describe the dielectric relaxation as well as the relaxation process caused by the restricted motion of the side groups at relatively low temperature. It is reasonable to conclude that the relaxation occurring in such composites is $\beta$ - relaxation originated mainly from lattices defects due to metal oxide ionization and electron transfer which lead to charged centers or polar bonds and groups or sites possessing polarization.

The frequency corresponding to maximum energy loss $F_{m}$ is used to calculate the relaxation time as equation (4) and hence activation enthalpies $\Delta \mathrm{H}$ and the entropy $\Delta \mathrm{S}$ from the relation (5) can be calculated. The calculated data are listed in Table 3. This table shows that the relaxation time decreases with increasing the temperatures for every sample explained above. The value of the enthalpy changes of the dielectric relaxation, which ranged from $11 \times 10^{3} \mathrm{KJ} / \mathrm{mole}$ for $\mathrm{H}_{2} \mathrm{Pc}$ to $18.5 \times 10^{3} \mathrm{KJ} / \mathrm{mole}$ for $\mathrm{ZnO}-\mathrm{Pc}$, which is in a good agreement with the previous definition of $\beta$ relaxation. The values of the entropy changes of dielectric relaxation $\Delta \mathrm{S}$ were the same also listed in Table 3, it can be seen that the values of $\Delta \mathrm{S}$ are all negative with low values, which means that the rate determining factor in the relaxation process includes the displacement of the free charges.
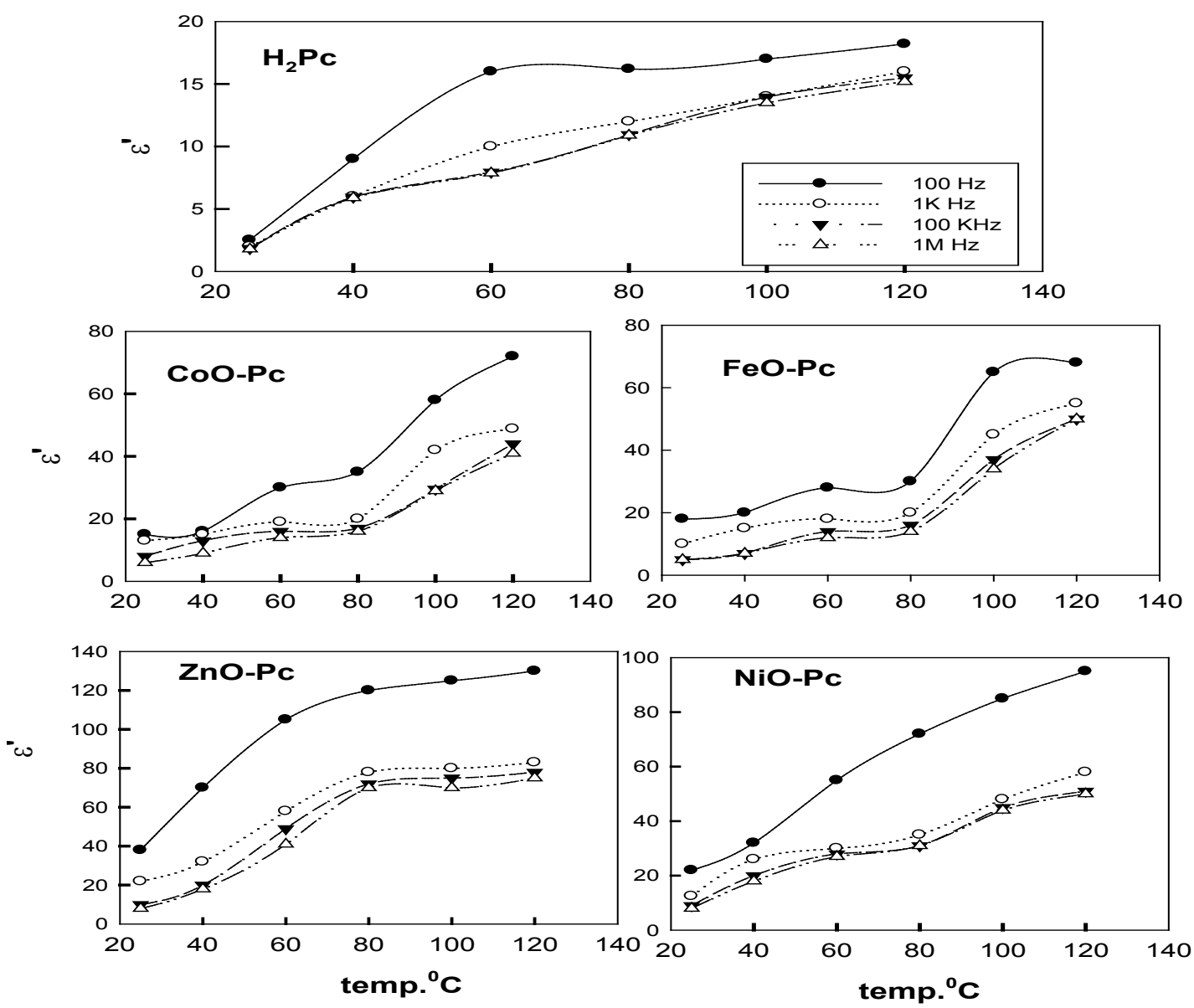

Fig.5.Variation of dielectric constant $\varepsilon^{\prime}$ with temperature at different frequencies for H2Pc and different MO-Pc. 


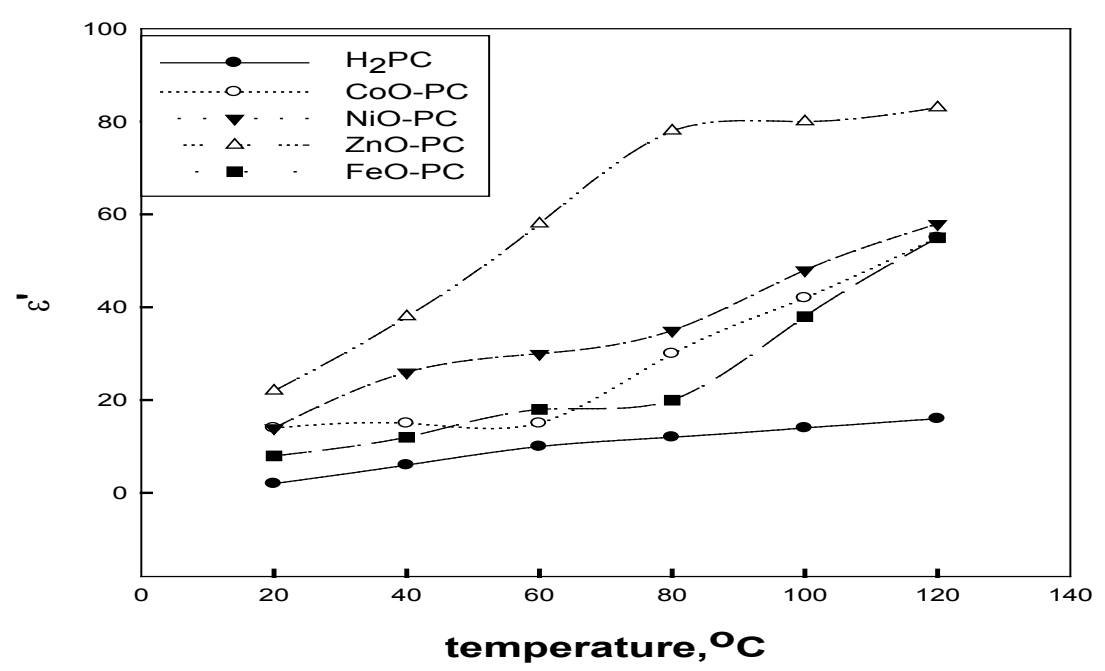

Fig.6.Variation of dielectric constant with temperature at $1000 \mathrm{~Hz}$ for $\mathrm{H} 2 \mathrm{Pc}$ and MO-Pc.

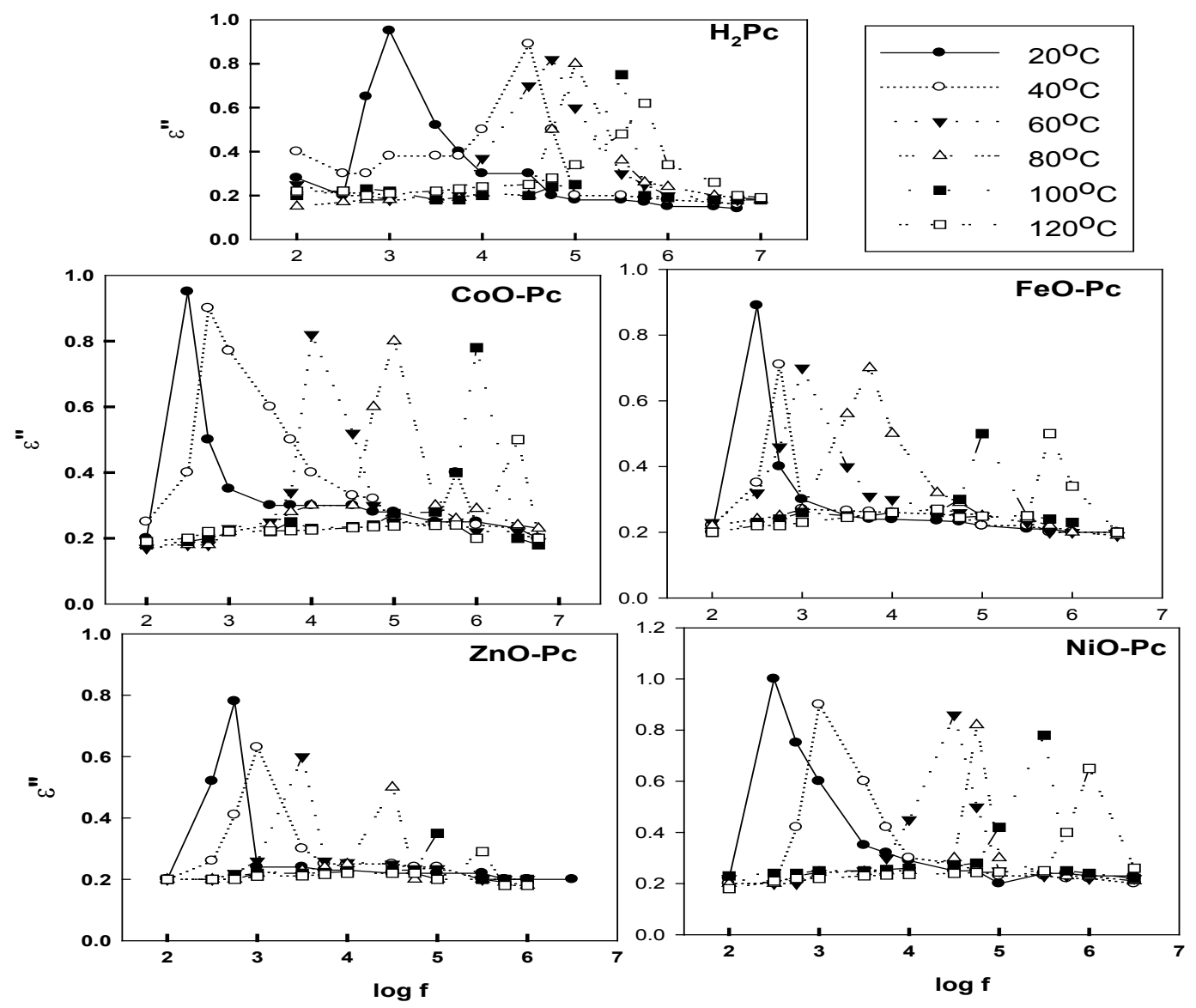

Fig.7. Variation of dielectric loss $\varepsilon^{\prime \prime}$ with frequency at different temperature for H2Pc and MO-Pc. 
TABLE 3.The relaxation time, Activation enthalpies $\Delta \mathrm{H}$ and the entropy changes $\Delta \mathrm{S}$ of the prepared MO-Pc composites.

\begin{tabular}{|c|c|c|c|c|c|c|c|c|}
\hline \multirow{2}{*}{$\begin{array}{c}\text { Prepared } \\
\text { samples } \\
\text { MO-Pc }\end{array}$} & \multicolumn{6}{|c|}{$\tau(\mathrm{sec})$} & \multirow{2}{*}{$\begin{array}{c}\Delta \mathrm{H} \\
\mathrm{KJ} / \mathrm{mole}\end{array}$} & \multirow{2}{*}{$\begin{array}{c}\Delta \mathrm{S} \\
\mathrm{J} / \mathrm{deg} / \mathrm{mole}\end{array}$} \\
\hline & $20^{\circ} \mathrm{C}$ & $40^{\circ} \mathrm{C}$ & $60^{\circ} \mathrm{C}$ & $80^{\circ} \mathrm{C}$ & $100^{\circ} \mathrm{C}$ & $120^{\circ} \mathrm{C}$ & & \\
\hline $\mathrm{H}_{2} \mathrm{Pc}$ & $\begin{array}{c}1.76 \times 10^{-} \\
4\end{array}$ & $3.19 \times 10^{-6}$ & $\begin{array}{c}1.59 \times 10^{-} \\
6\end{array}$ & $\begin{array}{c}5.31 \times 10^{-} \\
7\end{array}$ & $\begin{array}{c}2.28 \times 10^{-} \\
7\end{array}$ & $\begin{array}{c}3.19 \times 10^{-} \\
7\end{array}$ & $11.69 \times 10^{3}$ & 0.52 \\
\hline $\mathrm{CoO}-\mathrm{Pc}$ & $\begin{array}{c}2.27 \times 10^{-} \\
4\end{array}$ & $1.59 \times 10^{-4}$ & $\begin{array}{c}5.31 \times 10^{-} \\
7\end{array}$ & $\begin{array}{c}2.27 \times 10^{-} \\
7\end{array}$ & $\begin{array}{c}1.17 \times 10^{-} \\
7\end{array}$ & $\begin{array}{c}7.96 \times 10^{-} \\
8\end{array}$ & $16.19 \times 10^{3}$ & -10.43 \\
\hline $\mathrm{FeO}-\mathrm{Pc}$ & $5.3 \times 10^{-4}$ & $3.2 \times 10^{-4}$ & $1.8 \times 10^{-4}$ & $1.6 \times 10^{-4}$ & $\begin{array}{c}1.59 \times 10^{-} \\
6\end{array}$ & $\begin{array}{c}3.19 \times 10^{-} \\
7\end{array}$ & $17.52 \times 10^{3}$ & -12.05 \\
\hline $\mathrm{NiO}-\mathrm{Pc}$ & $\begin{array}{c}1.77 \times 10^{-} \\
4\end{array}$ & $1.59 \times 10^{-4}$ & $\begin{array}{c}5.31 \times 10^{-} \\
7\end{array}$ & $\begin{array}{c}3.18 \times 10^{-} \\
7\end{array}$ & $\begin{array}{c}2.27 \times 10^{-} \\
7\end{array}$ & $\begin{array}{c}1.77 \times 10^{-} \\
7\end{array}$ & $14.65 \times 10^{3}$ & -7.42 \\
\hline $\mathrm{ZnO}-\mathrm{Pc}$ & $5.3 \times 10^{-4}$ & $2.3 \times 10^{-4}$ & $\begin{array}{c}1.59 \times 10^{-} \\
4\end{array}$ & $\begin{array}{c}1.59 \times 10^{-} \\
6\end{array}$ & $\begin{array}{c}1.77 \times 10^{-} \\
7\end{array}$ & $\begin{array}{c}3.19 \times 10^{-} \\
7\end{array}$ & $18.49 \times 103$ & -10.93 \\
\hline
\end{tabular}

\section{Conclusion}

Phthalocyanine $\mathrm{H}_{2} \mathrm{Pc}$, and metal oxidephthalocyanine MO-Pc (where $\mathrm{MO}=\mathrm{FeO}$, $\mathrm{CoO}, \mathrm{NiO}$ and $\mathrm{ZnO}$ ) were prepared by urea fusion technique in the dry method. IR-spectra and diffraction X-ray analysis were done on the prepared composites to confirm their structure. XRD studies confirm the crystalline phase of $\mathrm{MO}-\mathrm{Pc}$ in order $\mathrm{ZnO}-\mathrm{Pc}>\mathrm{NiO}-\mathrm{Pc}>\mathrm{CoO}-\mathrm{Pc}>$ FeO-Pc. The crystal-linty increased particle size of $\mathrm{ZnO}-\mathrm{Pc}$ is ranged from $28.4 \mathrm{~nm}$ to $57.2 \mathrm{~nm}$ where it ranged from 51.4 to $82.4 \mathrm{~nm}$ for NiO-Pc

From the dielectric studies, it was concluded that the dielectric constant $\varepsilon^{\prime}$ is frequency and temperature dependent within the used ranges. The dependent of $\varepsilon^{\prime}$ values on metal oxide doping may be attributed to change in the free volume because we have different metal oxides with different atomic radii as well as the magnitude of dipole-dipole interaction and the segmental mobility.

The dielectric loss $\varepsilon$ " curves have an absorption maximum corresponding to the relaxation times. From the values of $\Delta \mathrm{H}$, it is reasonable to conclude that the relaxation occurring in such composites is $\beta$-relaxation originated from lattices defects due to ionization of metal oxide and transfer of electron which lead to charged centers and polar bonds $\mathrm{M}-\mathrm{O}$ and $\mathrm{M}-\mathrm{N}$. Relaxation times become shorter as the temperature increased indicates high availability of free charges.

The very low value of dielectric constant $\varepsilon$ ' at higher frequencies is important for the fabrication of materials towards ferroelectric, photonic and

Egypt.J.Chem. 61, No.2 (2018) electrooptic devices

\section{Acknowledgement}

The authors thank the National Research Centre for financial support (project number 11090305).

\section{References}

1. Sharman, W. M.; Van Lier, J. E., In the Porphyrin Handbook Academic Press: New York, 15, 1 -60. (2003).

2. Liu, F., Sun, J., Xiao, S., Huang, W., Tao, S., Zhang, Y., Gao,Y. and Yang, J. Controllable fabrication of copper phthalocyanine nanostructure crystals. Nanotechnology, 26 (22), 225601. (2015).

3. Takada, M., Yoshioka, H., Tada, H. and Matsushige, K. Electrical characteristics of phthalocyanine films prepared by electrophoretic deposition. Japanese Journal Of Applied Physics, 41(1A), L73. (2002).

4. Huo, L., Cao, L., Li, X., Li, W., Cui, H., Jiang, D. and Xi, S. Study of ferric oxide nanoparticles-tris(2,4-di-t-amylphenoxy)-(8-quinolinolyl)copper phthalocyanine composite LB film. Thin Solid Films, 365 (1), 129-133.(2000).

5. Ho, K. C. and Tsou, Y. H. Chemiresistor-type NO gas sensor based on nickel phthalocyanine thin films. Sensors and Actuators B: Chemical, 77 (1), 253-259. (2001).

6. Kim, J. Y. and Bard, A. J. Organic donor/acceptor heterojunction photovoltaic devices based on zinc phthalocyanine and a liquid crystalline perylene diimide. Chemical Physics Letters, 383(1), 11-15. (2004). 
7. Varotto, A., Nam, C. Y., Radivojevic, I., PC Tomé, J., Cavaleiro, J. A., Black, C. T., \& Drain, C. M. Phthalocyanine blends improve bulk heterojunction solar cells. Journal of the American Chemical Society, 132(8), 2552-2554, (2010).

8. Oku, T., Takeda, A., Nagata, A., Kidowaki, H., Kumada, K., Fujimoto, K.and Ōsawa, E. Microstructures and photovoltaic properties of C60 based solar cells with copper oxides, CuInS2, phthalocyanines, porphyrin, PVK, nanodiamond, germanium and exciton diffusion blocking layers. Materials Technology, 28(1-2), 21-39.) (2013).

9. Li, L., Tang, Q., Li, H., Hu, W., Yang, X., Shuai, Z., Liu,Y. and Zhu, D. Organic thin-film transistors of phthalocyanines. Pure and Applied Chemistry, 80(11), 2231-2240. (2008).

10. Yuen, A. P., Jovanovic, S. M., Hor, A. M., Klenkler, R. A., Devenyi, G. A., Loutfy, R. O. and Preston, J. S. Photovoltaic properties of M-phthalocyanine/fullerene organic solar cells. Solar Energy, 86(6), 1683-1688, (2012).

11. Zhi-lin, Z., Xue-yin, J., Wen-qing, Z., Bu-xin, Z., \& Shao-hong, X. A white organic light emitting diode with improved stability. Journal of Physics D: Applied Physics, 34(20), 3083. (2001).

12. Claessens, C. G., Hahn, U., \& Torres, T. Phthalocyanines: From outstanding electronic properties to emerging applications. The Chemical Record, 8 (2), 75-97. (2008).

13. Namita R., Methods of Preparation of Nanoparticles - A Review. International Journal of Advances in Engineering \& Technology, 7, 4, 1806-1811. (2015).

14. Ramesh, S., Sol-Gel Synthesis and Characterization of Nanoparticles. Journal of Nanoscience, 2013, 1-9. (2013).

15. Bian, S., Li, X., Shao, L. and Chen, J. Synthesis and photoconductivity of nanosized phthalocyanine. Journal of Materials Science and Technology, 22(4), 533-535. (2006).

16. Pinto, N. J., Acosta, A. A., Sinha, G. P. and Aliev, F. M. Dielectric permittivity study on weakly doped conducting polymers based on polyaniline and its derivatives. Synthetic Metals, 113 (1), 7781. (2000).

17. Devi, P. I., and Ramachandran, K. Dielectric studies on hybridised PVDF-ZnO nanocomposites. Journal of Experimental Nanoscience, 6 (3), 28129. (2011).
18. Konyushenko, E. N., Stejskal, J., Šeděnková, I., Trchová, M., Sapurina, I., Cieslar, M. and Prokeš, J. Polyaniline nanotubes: conditions of formation. Polymer International, 55(1), 31-39. (2006).

19. Latif, I., AL-Abodi, E. E., Badri, D. H. and Al Khafagi, J. Preparation, characterization and electrical study of (carboxymethylated polyvinyl alcohol/ZnO) nanocomposites. American Journal of Polymer Science, 2(6), 135-140, (2012).

20. Ojovan, M. I., Lee, W. B. E., Connectivity and glass transition in disorded oxide systems, $J$. of Non - Cryatalline Solids, 356 (44-49), 2534. (2010).

21. Xuan, S., Wang, Y. X. J., Leung, K. C. F. and Shu, K. Synthesis of Fe3O4@polyaniline core/shell microspheres with well-defined blackberry-like morphology. The Journal of Physical Chemistry C, 112(48), 18804-18809. (2008).

22. Kumar, S.and Jain, S. One-Step Synthesis of Superparamagnetic Fe3O4@ PANI Nanocomposites. Journal of Chemistry, 2014. (2014).

23. Hong, R. Y., Qian, J. Z. and Cao, J. X. Synthesis and characterization of PMMA grafted $\mathrm{ZnO}$ nanoparticles. Powder Technology, 163(3), 160168. (2006).

24. Gupta, A., Bhatti, H. S., Kumar, D., Verma, N. K. and Tandon, D. R. Nano and bulk crystals of $\mathrm{ZnO}$ : synthesis and characterization. Digest Int $J$ Nanomat Biostruct, 1, 1-9. (2006).

25. Stejskal, J. and Gilbert, R. G. Polyaniline. Preparation of a conducting polymer (IUPAC technical report). Pure and Applied Chemistry, 74(5), 857-867, (2002).

26. Ravikiran, Y. T., Lagare, M. T., Sairam, M., Mallikarjuna, N. N., Sreedhar, B., Manohar, S. and Aminabhavi, T. M., Synthesis, characterization and low frequency AC conduction of polyaniline/ niobium pentoxide composites. Synthetic Metals, 156 (16), 1139-1147, (2006).

27. Boyd, R. and Smith, G. Polymer Dynamics and Relaxation. Cambridge University Press. (2007).

28. Patsidis, A. and Psarras, G., Dielectric behaviour and functionality of polymer matrix-ceramic BaTiO3 composites. Currents, 5, 10, (2008).

29. Ramprasad, R. and Shi, N. Polarizability of phthalocyanine based molecular systems: A firstprinciples electronic structure study. Applied

Egypt.J.Chem. 61 , No.2 (2018) 
Physics Letters, 88 (22), 222903. (2006).

30. Liao, M. S. and Scheiner, S. Electronic structure and bonding in metal phthalocyanines, metal= $\mathrm{Fe}, \mathrm{Co}, \mathrm{Ni}, \mathrm{Cu}, \mathrm{Zn}, \mathrm{Mg}$. The Journal of Chemical Physics, 114 (22), 9780-9791. (2001).

31. Momida, H., Nigo, S., Kido and Ohno, T., Effect of vacancy - type oxygen deficiency on electronic structure in amorphous alumina, Appl. Phys. Let. 98, 042102. (2011).

32. Nigo, S., Kubota, M., Harada, Y., Hiraya, T., Kato, s., Kilazawa, H. and Kido, G., Conduction band caused by oxygen vacancies in aluminum oxide for resistance random access memory, $J$. Appl. Phys., 112, 033711. (2012).

33. Raju GG. Dielectrics in Electric Field. New York: Marcel Dekker Inc.; (2003)

34. Bhimasankaram T., Suryanarayana S.V. and Prasad G. Piezoelectric polymer composite materials. Curr Sci., 74, 967-76. (1998).

35. Dang, Z. M., Fan, L. Z., Zhao, S. J. and Nan, C. W. Preparation of nanosized $\mathrm{ZnO}$ and dielectric properties of composites filled with nanosized ZnO. Materials Science and Engineering: $B$, 99(1), 386-389. (2003).

36. Lestriez, B., Maazouz, A., Gerard, J. F., Sautereau, H., Boiteux, G., Seytre, G. and Kranbuehl, D. E. Is the Maxwell-Sillars-Wagner model reliable for describing the dielectric properties of a core-shell particle-epoxy system Polymer, 39 (26), 67336742. (1998)

37. Soares, B. G., Leyva, M. E., Barra, G. M. and Khastgir, D. Dielectric behavior of polyaniline synthesized by different techniques. European Polymer Journal, 42 (3), 676-686. (2006).

(Received 17/1/2018; accepted 22/2/2018)

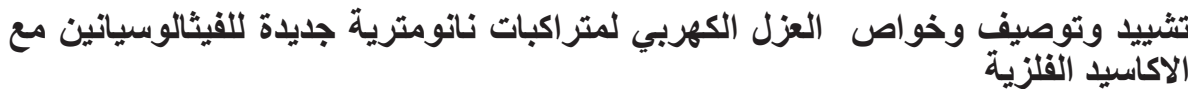

\author{
عاليه حسني سلامة وأمل محمد عبدالكريم \\ قسم الكيمياء الفيزيقيه ـ المركز القومي للبحوث ـ الجيزةة مصر.
}

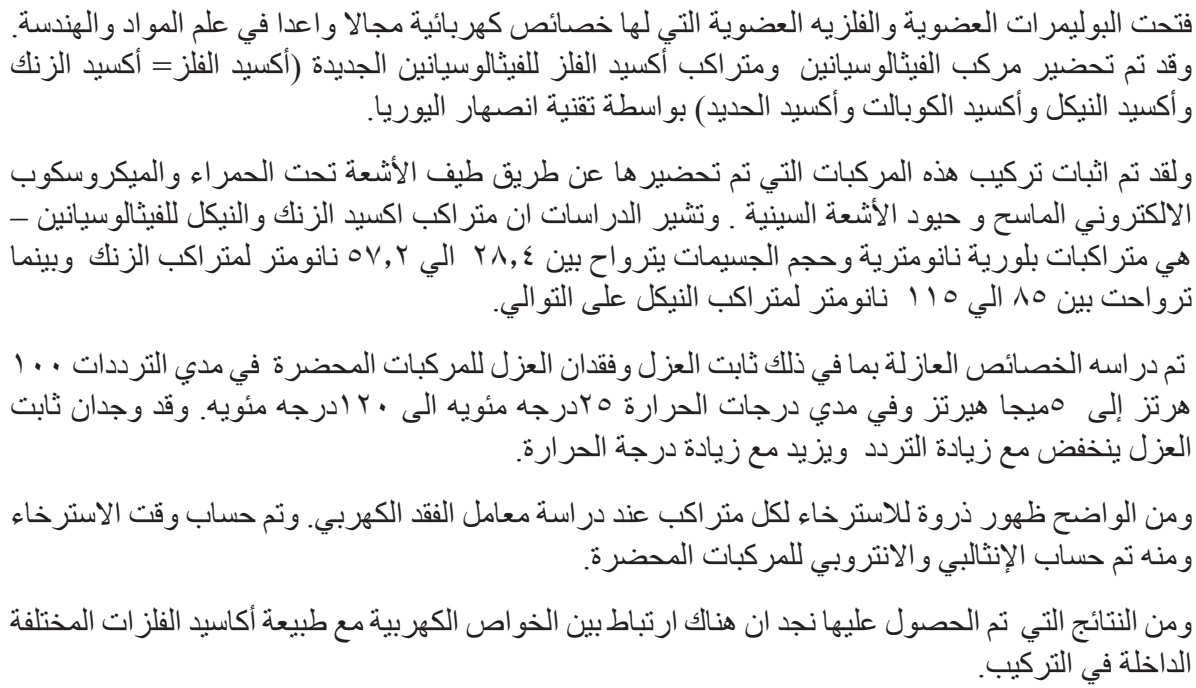

Egypt.J.Chem. 61, No.2 (2018) 